\title{
Identification of AFLP Markers Linked to Leaf Rust Resistance Genes Using Near Isogenic Lines of Wheat
}

\author{
Navjot Kaur Dhillon $^{1^{*}}$, Harcharan Singh Dhaliwal ${ }^{2}$ \\ ${ }^{1}$ Department of Plant Breeding and Genetics, Punjab Agricultural University, Ludhiana, India; ${ }^{2}$ Akal School of Biotechnology, Baru \\ Sahib, Himachal Pradesh, India. \\ Email: *dhillon.navjot@gmail.com
}

Received August 20 ${ }^{\text {th }}$, 2011; revised October 12 $2^{\text {th }}, 2011$; accepted October $30^{\text {th }}, 2011$.

\begin{abstract}
The present investigation was undertaken to find molecular markers linked to leaf rust resistance genes, Lr9 and Kharchia local mutant KLM4-3B. Preliminary AFLP analysis was carried out with different stocks, a survey of primer combinations with different selective nucleotide indicated that for each primer combination, the number of scorable loci ranged from 34 to 123. Only a limited primer combination used in the set of parental and near isogenic lines showed a high level of polymorphism for AFLP marker. Putative AFLP marker were found to be linked to Lr9, Lr19 and KLM43B. The alien genes were readily identified.
\end{abstract}

Keywords: AFLP, Leaf Rust, Wheat, Lr9, Isogenic Lines

\section{Introduction}

Wheat exceeds every other grain crop in acreage and production and is, therefore, the most important cereal of the world. With the introduction of semi-dwarf, photoinsensitive, fertilizer responsive and the high yielding varieties of wheat, the wheat production in India has increased from 12 million tonnes in 1966 to 85 million tonnes in the recent years. It is imperative to stabilize the wheat production by reducing the losses due to various diseases including leaf rust, stem rust, yellow rust, Karnal bunt etc. Among the diseases, leaf rust caused by Puccinia recondita Roberage ex. Desmaz f.sp. tritici is one of the most important and devastating foliar diseases of wheat which cause significant yield losses all over the world [1-8]. Breeding for resistance against leaf rust is an economical, efficient and environmentally safe control measure to reduce these losses [9]. Development of disease resistant varieties is one of the most economical methods of control of diseases like leaf rust. However, growing of rust resistant varieties having single gene for resistance results in rapid evolution of virulent biotypes of the pathogen, and thereby makes the resistance gene ineffective and the variety susceptible to rust. One of the ways to develop varieties with durable rust resistance is to pyramid the genes for resistance in a single variety
[10]. It is difficult to pyramid two or more disease resistance genes through conventional means, particularly where the resistance genes in question are effective against all the prevalent pathotypes. However, recent advances in molecular biology has made it possible to pyramid several genes in single line using marker assisted selection (MAS) and tagging of genes with molecular markers is pre-requisite for MAS [11].

A number of rust resistance genes, including leaf rust, have been transferred from wild relatives of wheat into cultivated wheats $[12,13]$. In India, from the analyses of 2630 samples collected from 17 states, one union territory and Nepal from 2005 to 2008, 31 races were identified among which eight were new [14]. Most of which could not be exploited because of extensive linkage drag. One of the leaf rust resistance genes, Lr9 transferred from Aegilops umbellulata [15] located on chromosome 6BL, has no undesirable effect associated with it [16]. This gene is effective against all the races of leaf rust currently prevalent in northern India. Similarly, another leaf rust resistance gene identified in (Kharchia local mutant KLM4-3B) is also effective against all the prevalent leaf rust pathotypes in northern India.

Keeping this in view the present study was undertaken to identify molecular markers linked with $\operatorname{Lr} 9, \operatorname{Lr} 19$ and 
KLM4-3B as these genes provide resistance against most of the leaf rust pathotypes of the Indian subcontinent.

\section{Materials and Methods}

\subsection{Plant Material}

Near-isogenic lines carrying the leaf rust resistance genes Lr9, Lr19 and the leaf rust resistant gene of KLM4-3B in the background of WL711 developed at the School of Biotechnology were used along with the donor and the recurrent parents for identifying AFLP markers linked to the two genes.

\subsection{Genomic DNA Isolation}

Approximately $5 \mathrm{~g}$ fresh weight of young leaves were harvested from plants grown in the field and DNA was extracted as per the method of Dellaporta [17].

\subsection{Amplified Fragment Length Polymorphism (AFLP) Analysis}

AFLP analysis was carried out according to procedures of Vos et al. (1995) [18] with minor modifications. The genomic DNA was restricted with two enzymes, a 6-base (rare) cutter Pstl and a 4-base (frequent) cutter Mse1 at $37^{\circ} \mathrm{C}$. The Pst1 and Mse1adapters were ligated to the fragment ends; amplifying a subset of Msel-Pstl fragments with primers that match the adapter and contain additional selective nucleotide at the 3 ' end; and separating the fragments on denaturing polyacrylamide gel (6\%). Sequence of adapters and the primers used for AFLP analysis are given in Table 1. To achieve selective amplification of a subset of these fragments, 10 cycles of PCR amplification under following parameters. Thirty seconds denaturation at $94^{\circ} \mathrm{C}$, thirty seconds primer an nealing at $65^{\circ} \mathrm{C}$ and decreasing one degree temperature in every subsequent cycles and one minute primer extention at $72^{\circ} \mathrm{C}$.

\subsection{Separation of Amplified Fragments on Denaturing Polyacrylamide Gel}

An equal volume of formamide loading buffer (96\% formamide, $10 \mathrm{mM}$ EDTA pH 8.0, \% 0.1 fuchsin) was added to the samples and denatured at $94^{\circ} \mathrm{C}$ at $1.5 \mathrm{~min}$. A $25 \mathrm{~cm}$, 8\% denaturing polyacrylamide gel (Long Ranger) was prepared and preheated for $20 \mathrm{~min}$. 1.0 _L of each samples was loaded on to the gel and electrophoresis was conducted in 1 x Long Run TBE buffer at $1.500 \mathrm{~V}, 40 \mathrm{~W}$, $40 \mathrm{~mA}$ and $50^{\circ} \mathrm{C}$ using a Li-Cor DNA Gene Readir 4200 (MWG Biotech. Ebersberg/Germany).

\section{Results and Discussion}

\section{AFLP Analysis}

Preliminary AFLP analysis was carried out with different stocks including recurrent parent WL711, Thatcher + Lr9 and LrKLM4-3B and isogenic lines i.e. WL $711+\operatorname{Lr} 9$ and WL $711+$ Lr KLM4-3B. KLM4-3B, along with these stocks, analysis of HD 2329, Agatha (Lrl9) and isogenic line WL 711. A survey of primer combinations with different selective nucleotide indicated that for each primer combination, the number of scorable loci ranged from 34 to 123 (Table 2). Total number of marker loci scored with different primer combination were 682 for WL 711, 629 for HD 2329, 611 for Thatcher+Lr9, 515 for Agatha (Lr19), 582 for $\operatorname{Lr}$ KLM4-3B, 629 for WL $711+L r 9$, 516 for WL $711+L r 19$ and 599 for WL $711+L r$ KLM4-3B (Table 2). So, minimum number of marker loci (515) amplified were from Agatha (Lr19) stock and

Table 1. Sequence of the adapters and primers used for pre-amplification and selective amplification.

\begin{tabular}{|c|c|}
\hline Purpose & Oligonucleotide sequences \\
\hline \multicolumn{2}{|l|}{ Adapters } \\
\hline Pstl-Adapter-Sequence & $\begin{array}{c}\text { 5' -CTCGTAGACTGCGTACATGCA-3' } \\
\text { 3' -CATCTGACGCATGT-5' }\end{array}$ \\
\hline Msel-Adapter-Sequence & $\begin{array}{l}\text { 5' -GACGATGAGTCCTGAG- 3' } \\
\text { 3' -TACTCAGGACTCAT-5' }\end{array}$ \\
\hline \multicolumn{2}{|l|}{ Primers for preamplification } \\
\hline Pstl-primer & 5' -GACTGCGTACATGCAGA-3' \\
\hline Msel-primer & 5' -GATGAGTCCTGAGTAAC-3' \\
\hline \multicolumn{2}{|c|}{ Primers for selective amplification } \\
\hline Pstl-primer + ACT & 5' -GACTGCGTACATGCAGACT- 3' \\
\hline Pstl-primer + ACC & 5' -GACTGCGTACATGCAGACC-3' \\
\hline Msel-primer + CAA & 5' -GATGAGTCCTGAGTAACAA-3' \\
\hline Msel-primer + CTA & 5' -GATGAGTCCTGAGTAACTA-3' \\
\hline Msel primer + CTG & 5' -GATGAGTCCTGAGTAACTG-3' \\
\hline Msel primer + CTT & 5' -GATGAGTCCTGAGTAACTT-3' \\
\hline
\end{tabular}


Table 2. Number of AFLP loci scored in different stocks using different primer combinations.

\begin{tabular}{ccccccccc}
\hline Primer combination & $\begin{array}{c}\text { T. aestivum } \\
\text { WL 711 }\end{array}$ & $\begin{array}{c}\text { T. aestivum } \\
\text { HD 2329 }\end{array}$ & $\begin{array}{c}\text { Thatcher } \\
+ \text { Lr9 }\end{array}$ & $\begin{array}{c}\text { Agatha } \\
\text { (Lr19) }\end{array}$ & KML 4-3B & $\begin{array}{c}\text { WL711 + } \\
\text { Lr9 }\end{array}$ & $\begin{array}{c}\text { WL711 + } \\
\text { Lr19 }\end{array}$ & $\begin{array}{c}\text { WL711 + } \\
\text { LrKLM4-3B }\end{array}$ \\
\hline Pst1 + ACC/Mse1 + CTB & 110 & 98 & 107 & 70 & 104 & 111 & 78 & 110 \\
Pst1 + ACC/Mse1 + CTA & 119 & 123 & 98 & 98 & 121 & 100 & 103 & 108 \\
Pst1 + ACC/Mse1 + CAA & 98 & 51 & 96 & 34 & 49 & 97 & 40 & 50 \\
Pst1 + ACC/Mse1 + CTG & 67 & 67 & 43 & 59 & 52 & 49 & 49 & 63 \\
Pst1 + ACC/Mse1 + CTA & 79 & 82 & 75 & 94 & 71 & 79 & 89 & 77 \\
Pst1 + ACC/Mse1 + CTT & 108 & 110 & 92 & 84 & 91 & 94 & 82 & 85 \\
Pst1 + ACC/Mse1 + CTA & 101 & 98 & 100 & 76 & 94 & 99 & 75 & 96 \\
Total number of loci & $\mathbf{6 8 2}$ & $\mathbf{6 2 9}$ & $\mathbf{6 1 1}$ & $\mathbf{5 1 5}$ & $\mathbf{5 8 2}$ & $\mathbf{6 2 9}$ & $\mathbf{6 1 6}$ & $\mathbf{5 9 9}$ \\
\hline
\end{tabular}

maximum (682) in case of WL 711.

Number of conserved sequence markers were scored separately for different primer combination and it was found that primer Pstl + ACC/Mse1 +CTG amplified 35 sequences common to all the used, whereas Pstl + ACC/ Mse1 + CTG amplified 56, Pstl + ACT/Mse1 + CAA amplified 24, Pstl + ACT/Mse1 + CTG amplified 26 and Pstl + ACTI Msel + CTA amplified 32 common sequences. Out of 110 scorable markers (Figure 1) amplified by Pstl + ACC/Mse1 + CTG, only one marker (Figure 1(a)) was found to be specific in LrKLM4-3B and WL $711+$ LrKLM4-3B and were not amplified in any of the other stocks. Further, it was seen that primer combination Pstl + ACT/Msel + CTT amplified three markers (Figures 2(b)-(d)) which were specifically amplified in Agatha (Lr19) and in isogenic line, WL $711+$ Lr19 and were not amplified in any of the other stocks (Figure 2). Only a limited primer combination used in the set of parental and near isogenic lines showed a high level of polymorphism for AFLP marker as compared to RAPD [19]. Putative AFLP marker linked to $\operatorname{Lr} 9$ and $\operatorname{Lr} 19$, the alien genes were readily identified. These primer combinations need to be tried on the relevant $F_{2}$ population or RILs for estimation of extent of association before development of STS primers for MAS.

This technique was utilized to clone and map variety specific rice genomic DNA sequence [20]. Many other workers has used this technique in the past for detecting polymorphism, DNA fingerprinting, molecular typing [21,22], genome mapping [19,23], gene tagging [24], genetic diversity analysis [25] and gene expression analysis [26]. AFLP technique for classification of rice germplasm by fingerprinting cytoplasmic male sterile lines of rice was performed and found that the banding pattern of AFLP markers were remarkably consistent [27]. The duplicated CMS lines shared every AFLP band and were thus confirmed as identical genotypes. Thus AFLP analysis conducted in the present study were found to be useful tools in identification of putatively linked markers

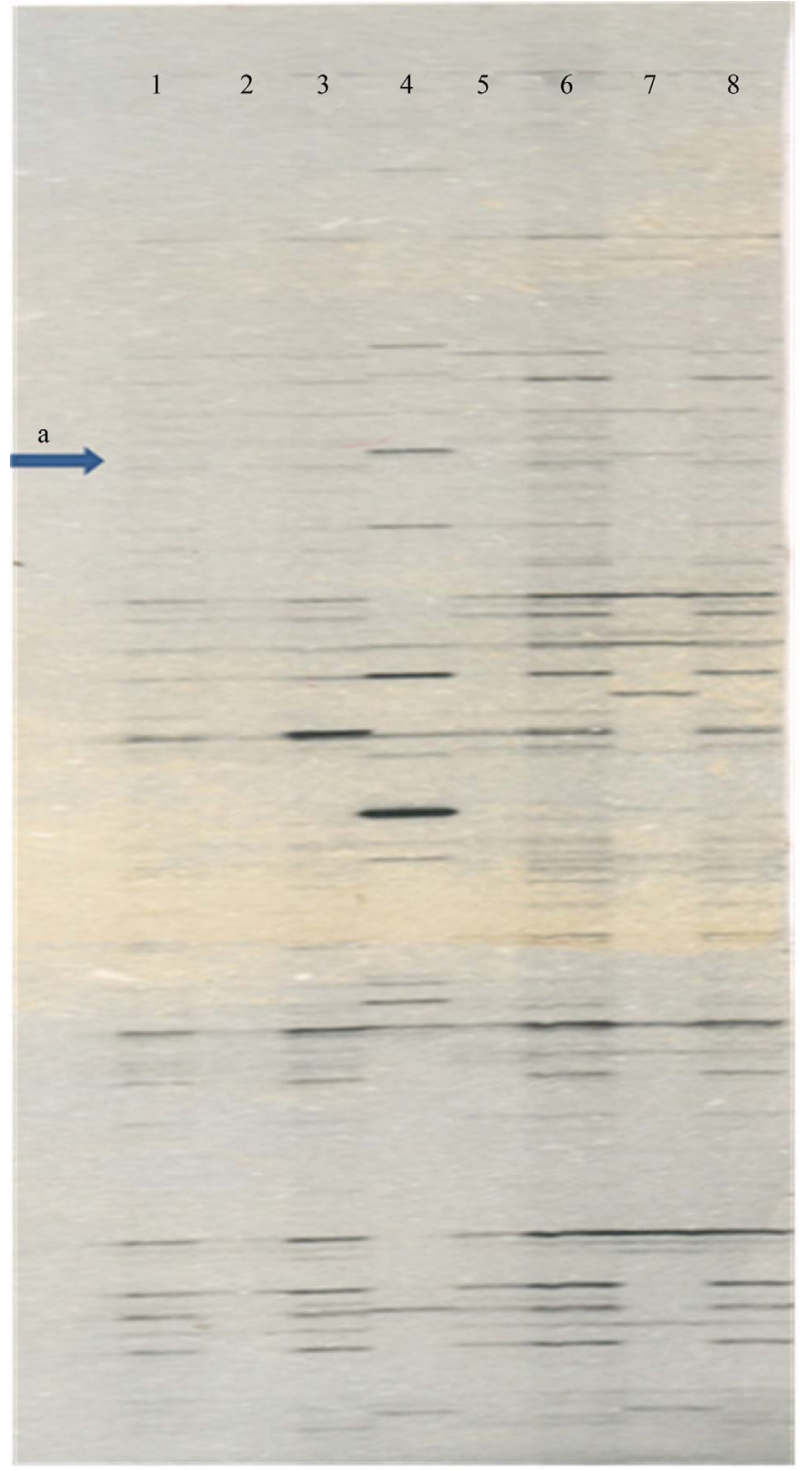

Figure 1. AFLP markers amplified by primer combination Pst1 + ACC/Mse1 + CTG. Lanes 1-8: WL711, HD2329, Thatcher +Lr9, LrKLM4-3B, Agatha (Lr19), WL711 + Lr9, WL711 + LrKLM4-3B, WL711 + Lr19. 


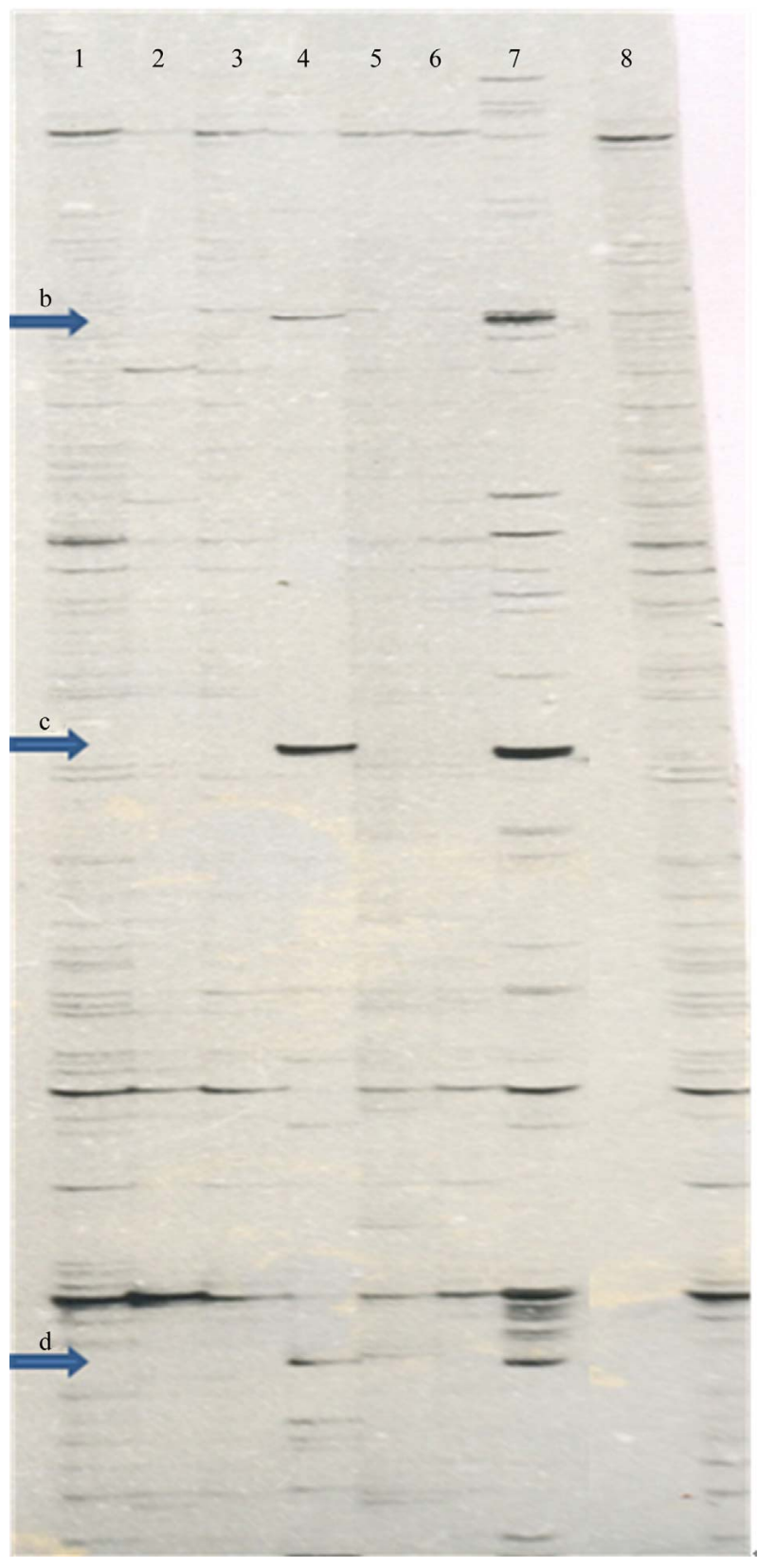

Figure 2. AFLP markers amplified by primer combination Pst1 + ACT/Mse1 + CTT. Lanes 1-8: WL711, HD2329, Thatcher +Lr9, Agatha (Lr19), LrKLM4-3B, WL711 + Lr9, WL711 + Lr19, WL711 + LrKLM4-3B.

to different leaf rust resistant genes. This high reproducebility, rapid generation and high frequency of identifiable AFLP polymorphic bands makes AFLP analysis an attractive approach for molecular analysis in different organisms.

\section{REFERENCES}

[1] M. G. Eversmeyer and L. E. Browder, "Effect of Leaf and Stem Rust on 1973 Kansaswheat Yields,” Plant Disease Reporter, Vol. 58, No. 5, 1974, pp. 469-471.

[2] R. G. Saini and A. K. Gupta, "Genes for Resistance to Brown Rust Puccinia recondita) in Wheat. II. Lr Genes in Frontana, WG138 and E6360," Cereal Research Communications, Vol. 7, 1979, pp. 289-291.

[3] D. Anand, R. G. Saini and A. K. Gupta, "Slow Leaf Rust Development Due to Combination of Some Genes in Wheat,” Plant Disease Reporter, Vol. 3, 1988, p. 97.

[4] M. Seck, A. P. Roelfs and P. S. Teng, "Effect of Leaf Rust Puccinia recondite Triticii on Yield of Four Isogenic Wheat Lines,” Crop Protection, Vol. 7, No. 1, 1988, pp. 39-43. doi:10.1016/0261-2194(88)90036-1

[5] K. V. S. Rao, J. P. Snow and G. T. Berggren, "Effect or Growth Stage and Initial Inoculum Level on Leaf Rust Development and Yield Loss Caused by Puccinia recondita f. sp. tritici," Journal of Phytopathology, Vol. 127, No. 3, 1989, pp. 200-210. doi:10.1111/j.1439-0434.1989.tb01130.x

[6] R. P. Singh, J. Huerta-Espino, W. Pfeiffer and P. F. Lopez, "Occurrence and Impact of a New Leaf Rust Race on Durum Wheat in Northwestern Mexico from 2001 to 2003,” Plant Disease, Vol. 88, No. 7, 2004, pp. 703-708. doi:10.1094/PDIS.2004.88.7.703

[7] J. A. Appel, E. DeWolf, W. W. Bockus and T. Todd, "Kansas Cooperative Plant Disease Survey Report Preliminary Kansas Wheat Disease Loss Estimates," August 11, 2009. http:// www.ksda.gov/includes/document center/plant_protection/Plant\%20Disease20Reports/2009KS WheatDiseaseLossEstimates.pdf. Accessed 29 November 2010.

[8] G. V. Volkova, T. P. Alekseeva, L. K. Anpilogova, M. V. Dobryanskaya, O. F. Vaganova and D. A. Kol’bin, "Phytopathological Characteristics of Leaf Rust Resistance of New Winter Wheat Varieties,” Russian Agricultural Sciences, Vol. 35, No. 3, 2009, pp. 168-171. doi:10.3103/S1068367409030112

[9] J. H. Espino, R. P. Singh, S. Germa'n, B. D. McCallum, R. F. Park, Q. W. S. Chen, C. Bhardwaj and H. Goyeau, "Global Status of Wheat Leaf Rust Caused by Puccinia triticina,” Euphytica, Vol. 179, No. 1, 2011, pp. 143-160. doi:10.1007/s10681-011-0361-x

[10] I. Lowe, D. Cantu and J. Dubcovsky, "Durable Resistance to the Wheat Rusts: Integrating Systems Biology and Traditional Phenotype-Based Research Methods to Guide the Deployment of Resistance Genes,” Euphytica, Vol. 179, No. 1, 2011, pp. 69-79. doi:10.1007/s10681-010-0311-z

[11] L. Huang, L. Q. Zhang, B. L. Liu, Z. H. Yan, B. Zhang, H. G. Y. L Zhang and D. C. Liu, "Molecular Tagging of a Stripe Rust Resistance Gene in Aegilops Tauschii," Euphytica, Vol. 179, No. 2, 2011, pp. 313-318. doi:10.1007/s10681-010-0330-9

[12] M. Baum, E. S. Laguadah and R. Appels, "Wide Crosses in Cereals," Annual Review of Plant Physiology and Plant Molecular Biology, Vol. 43, 1992, pp. 117-143. doi:10.1146/annurev.pp.43.060192.001001 
[13] Z. A. Pretorius and C. M. Bender, "First Report of Virulence for the Wheat Leaf Rust (Puccinia triticina) Resistance Gene Lr32 in South Africa,” Plant Disease, Vol. 94, No. 3, 2010, pp. 381. doi:10.1094/PDIS-94-3-0381A

[14] S. C. Bhardwaj, M. Prashar, S. K. Jain, S. Kumar, Y. P. Sharma, "Physiologic Specialization of Puccinia Triticina on Wheat (Triticum Species) in India," Indian Journal of Agricultural Sciences, Vol. 80, 2010, pp. 805-881.

[15] E. R. Sears, "The Transfer of Leaf Rust Resistance from Aegilops umbellulata into Wheat,” Brookhaven Symposia in Biology, Vol. 9, 1956, pp. 1-21.

[16] A. S. Soliman, E. Y. Heyne and C. O. Johnston, "Resistance to Leaf Rust in Wheat Derived from Chinese Aegilops umbellulata Translocation Lines," Crop Science, Vol. 3, 1963, pp. 254-256. doi:10.2135/cropsci1963.0011183X000300030025x

[17] S. L. Dellaporta, J. Wood and J. B. Hicks, "A Plant DNA Mini Preparation. Version 11,” Plant Molecular Biology Reporter, Vol. 1, No. 4, 1983, pp. 19-21. doi:10.1007/BF02712670

[18] P. Vos, R. Hogers, M. Bleeker, M. Reijans, T. V. D. Lee, M. Hornes, A. Frijters, J. Pot, J. Peleman, M. Kuiper and M. Zabeau, “AFLP: A New Technique for DNA Fingerprinting” Nucleic Acids Research, Vol. 23, No. 21, 1995, pp. 4407-4414. doi:10.1093/nar/23.21.4407

[19] D. J. Mackill, Z. Zang, E. D. Redona and P. M. Colowit, "Level of Polymorphism and Genetic Mapping of AFLP Markers in Rice,” Genome, Vol. 39, No. 5, 1996, pp. 967-977. doi:10.1139/g96-121

[20] Y. Cho, M. Blair, O. Panaud and S. R. McCouch, "Cloning and Mapping of Variety-Specific Rice Genomic Sequences: Amplified Fragment Length Polymorphism (AFLP) from Silver-Staired Polyacrylamide Gels,” $G e$ nome, Vol. 40, 1996, pp. 84-91.

[21] J. J. Lin, J. Kuo and J. Ma, “A PCR-Based DNA Fingerprinting Technique: AFLP for Molecular Typing of Bac- teria,” Nucleic Acids Research, Vol. 4, No. 18, 1996, pp. 3649- 3650. doi:10.1093/nar/24.18.3649

[22] M. Maheswaran, P. K. Subudhi, S. Nandi, J. C. Xu, A. Parco, D. C. Yang and N. Huang, "Polymorphism, Distribution and Segregation of AFLP Markers in a Double Haploid Rice Population,” Theoretical and Applied Genetics, Vol. 94, No. 1, 1996, pp. 39-45. doi:10.1007/s001220050379

[23] J. Becker, P. Vos, M. Kuiper, F. Salamini and M. Heun, "Combined Mapping of AFLP and RFLP Markers in Barley,” Molecular and General Genetics, Vol. 249, No. 1, 1995, pp. 65-73. doi:10.1007/BF00290237

[24] C. M. Thomas, P. Vos, M. Zabeau, D. A. Jones, K. A. Norcott, B. P. Chadwick and J. D. G. Jones, "Identification of Amplified Restriction Fragment Polymorphism (AFLP) Markers Tightly Linked to the Tomato Cf-9 Gene for Resistance to Cladosporium fulvum," Plant Journal, Vol. 8, No. 5, 1995, pp. 785-794. doi:10.1046/j.1365-313X.1995.08050785.x

[25] E. D. Redona, L. R. Hipotita, R. A. Caldo and L. S. Sebastian, "Utilization of AFLPs for Genetic Diversity Analysis. The Case for Progenitor Cultivars of Modern Philippine Rice Varieties,” Asian Rice Biotechnology Network Course on AFLPs for Rice Improvement, Philippine Rice Research Institute (Phil Rice)m Maligaya, Nunoz, Nueva Ecija 3119, IRRI, 1996.

[26] C. Bachem, W. B. Hoeven, R. S. Vander, S. M. Bruijn, D. Vrueugdenkil, M. Zabeau and R. G. F. Visser, "Visualization of Differential Gene Expression Using a Novel Method of RNA Fingerprinting Based on AFLP : Analysis of Gene Expression during Potato Tuber Development,” Plant Journal, Vol. 9, No. 5, 1996, pp. 745-753. doi:10.1046/j.1365-313X.1996.9050745.X

[27] P. K. Subudhi, S. Nandi, C. Casal, S. S. Virani and N. Huang, "Classification of Rice Germplasm II: High Resolution Fingerprinting of Cytoplasmic Genetic Male Sterile (CMS) Lines With AFLP,” Theoretical and Applied Genetics, Vol. 94, 1996, pp. 160-169. 